\title{
Setu lüroeepiliste regilaulude eepilisest kihist $\stackrel{*}{-}$
}

\section{Madis Arukask}

Üht osa eesti ja setu regilauluvaramust on traditsiooniliselt peetud lüroeepiliseks. Jakob Hurda "Setukeste laulude" esimeses köites oli see osa jagatud nelja erinevasse rubriiki ja pealkirjastatud muinasusuliste, ristiusuliste, muinasjutuliste ja ilujutuliste lauludena (vt Hurt 1904).

Kirjandusteadusliku definitsiooni järgi on lüroeepika puhul tegemist liitliigiga, milles põimuvad lüürika ja eepika, kusjuures lürism avaldub ennekõike lüüriliste kõrvalepõigetena eepilisest teemaarendusest. Käesoleva ettekande eesmärgiks on mõnevõrra lähemalt vaadelda setu lüroeepiliste regilaulude eepilise poole mõningaid aspekte.

Regilaulu vanust on hinnatud kuni mõne aastatuhandega. On ilmne, et see on vaid regilaulu vormipoole umbkaudne vanus. Kuigi kalevalameetrilised värsid, mida läänemeresoomlased laulnud on, pole vanemad kui 3000-3500 aastat, võivad selle tagapõhjaks olnud proosavormis müüdid, mida rahvad on rääkinud, tantsinud või muul moel esitanud, vanemad olla (Pentikäinen 1986: 203). Juri Lotmani järgi olid mütoloogilised tekstid kõrge ritualiseeritusastmega ning käsitlesid maailmakorralduse aluseid, maailma tekkimise ja eksisteerimise seaduspärasusi (Lotman 1991: 323). Ka regilaulus on tuttavad loomise, taevaste kosjade, ilmakorra rikkumise jms motiivid. Seega võib olla kindel, et vanima eepilise kihi laulus moodustab müüt ja müüdiline mõtlemine.

Müüdilise mõttelaadi taandumisega on üldjuhul alati toimunud ka uue esteetilise väljendusvormi pealetulek. Nii näiteks võime Vanema Edda näiteil jälgida, kuidas ilmaloomise-aegsetest tegelastest saavad järk-järgult kangelaseepilised seiklejad. Sellist transformeerumist võime näha ka Kalevalaeepika ja selle peategelaste (Väinämöinen, Ilmarinen) puhul (vrd Annist 1985: 485-486) Selle taustal oleks ootuspärane leida kangelaseepika kajastusi ka eesti ja setu lüroeepilistes regilauludes.

Regilaulu lõikes moodustab noorima eepilise kihistuse ballaad ja ballaadikangelane - eepilist aegruumi lõhkuvad ja vanu vormeleid uueneva kaasajaga kohandada püüdvad ilmingud. Seega võiksime regilaulu jutulise tausta muutumise kõige üldisemalt paigutada järgmisele arenguskeemile:

$$
\text { müüt --> kangelaseepika --> ballaad }
$$

Selle taustsüsteemi silmaspidamine on vajalik, kuivõrd regilaul ei kujuta endast tavalist, kindla loomishetkega suhtestatavat kunstiteost, vaid ajas pidevalt muutunud, "laiali venitatud" fenomeni, millest meieni on üleskirjutustena jõudnud vaid praktiliselt viimaseid kujusid alates eelmise sajandi keskpaigast. 
Pöördudes küsimuse juurde, kui kõnekas on lüroeepiline regilaul narratiivina, peaksime vaatlema jutu seisukohalt paari tähtsamat komponenti:

1. kangelast ehk peategelast,

2. konflikti või intriigi kui sündmustiku käivitajat mistahes loos.

Iga lüroeepiline laulutüüp suhtestub meie poolt varem väljajoonistatud arengutausta erinevalt. Setu lüroeepikas on kõige kindlama ja stabiilsema süzheega lauludeks nimelise (pea)tegelasega markeeritud lood, eelkõige "Toomalaul", "Maielaul", "Kalmuneiu". Need on reeglina traagilise sisuga, milles peategelane on võetav indiviidi, mitte aga mingit laiemat ideoloogiat kandva eepilise koondportreena. Üldjuhul on need laulutüübid ka süzheeliselt stabiilsemad, mis pole sugugi iseloomulik kogu setu lüroeepikale. Ühteaegu pole nad võetavad puhaste ballaadidena, mida iseloomustaks kontsentreeritus või eklektilisus (vrd Merilai 1991: 8) - millele ei anna võimalust regilaulu vormispetsiifika - kordused, paralleelvärsid jt suulisele eepikatraditsioonile omased võtted. Sellegipoolest on ilmne, et keskendutud on loo jutustamisele.

"Toomalaulus" on olemas nii positiivne kangelane - Tooma naine, kes esindab ballaadliku "õilsa kannataja" poolt - kui ka antagonist - Toomas oma deemonliku abilisega. Toomas soovib oma naise surma, kui tal on kaasast villand või kui see on juba lapse saanud. Kõrtsis sellest kõneldes pakub talle teenet must mees - algselt tõenäoliselt mõni ristiusu-eelne deemonlik tegelane (Valk 1994: 9), kes korraldab ka tapmise. Naise omaksed maksavad Toomale kätte, põletades ta tulel. Naise surm ja ta fatalistlik saatusele vastuminek on ballaadliku traagika haripunktiks. Kogu loos jääb moraaalseks võitjaks ohver, olles nii ka ballaadi kangelaseks. Ehkki laul kannab Tooma nime, on selle tegelik peategelane nimetu "naine«, veel enam - noor naine, kellega lauljal on kerge samastuda (Virtanen 1974: 501).

Ka "Kalmuneius" on süzhee varianditi vähevarieeruv. Peeter rikub kalmule antud lubadust sealt naine kosida, edasine on vaid tema karistuse ja allakäigu lugu. Olles oma pruudiga koduteel, peatub ta regi kalmul ja kalmulised nõuvad talt lubaduse täitmist. Peetril ei jää üle muud kui lubada neile oma noorik ning nii saabubki ta koju surnud pruudiga. Kunagine mütoloogiline reaalia - kalmulised, allilma elanikud - on järjest nihkunud sümboli suunas. Peeter kui erakorraline eksija paneb laulus endale kaasa tundma. Ballaadi lõpuosas nihkub aga peategelase roll enam Peetri ema suunas kuivõrd on eksponeeritud tema ahastust poja saatuse pärast. Seega on siin tuntav tendents narratiivi lagunemisele naiseliku interpretatsiooni tõttu, mis on üritanud võimalikku müüdilist arhetüüpi individualiseeritud maailmanägemuses üle luua.

Erinevalt eelmistest pole "Maielaulu" kangelanna sugugi nii üheselt määratletav. Tihti arusaamatul põhjusel (ebasümpaatia?) tapab Maie ettekavatsetult oma mehe, kellega just abiellus. Mõrv tuleb ilmsiks ja Maie põgeneb, küsides varju teel ettejäävatelt puudelt, kes üldjuhul keelduvad seda pakkumast. Põgenedes kahetseb Maie oma tegu. Näib jällegi, et naislaulik pole suutnud Maiele ühest hinnangut anda ja sellise kontseptuaalse nõrkuse tõttu lonkab kogu lugu. Mehetapjana esindaks Maie muinasjutulikku antagonisti, järgnevas põgenemisloos meenutab ta jälle rohkem tagakiusatavat ballaadikangelannat. Ehkki loos on sees intriig (mehetapmine) ning on käivitunud sündmustik (põgenemine, varju otsimine), jääb kogu arendus jutu seisukohalt poolikuks. Seega on jutulik poolus siin hägustunud ja leidnud kasutamist formaalse materjalina laulmiseks kui selliseks. 
Vaadeldud lauludes on vaatamata kõigele järel see kriitiline hulk eepilist osist, mis teeb nende jälgimise või lugemise võimalikuks ka tänasele lugejale. Kompositsiooniliselt jutulike tervikutena on nad lauljatele kajastunud ka seetõttu, et varianditi ei ole just totaalseid lahkuminekuid süzheedes, variandid on äratuntavad sama skeemi (Parry-Lordi ehk vormeliteooriast tuttava story-pattern'i) esitustena.

Vaadelgem nüüd ballaadikaugemaid laulutüüpe. Kui juba "Maielaulus" võisime jälgida lõpuni ladusa loo puudumist, ilmneb see joon veelgi enam lauludes, kus esineb enam üleloomulikku atribuutikat, transformatsioone, kosmilisi ümberpaiknemisi.

"Leemelehe" variandid on küllalt ühtlased. Hommikul metsa läinud õde annab tõotusi müstilisele leemelehele-aupaberile, et seda endale saada. See õnnestub tal alles siis, kui ta on lubanud oma kodu ja venna. Järgneb teekond kodukohta, mille vältel ta saab teada kodu ja venna kadumisest ning järve(de)st nende asemel. Järgneb kahetsus või needmine, ühes variandis saab ta kodu ja venna ka tagasi, mis on küllap erandlik. Seega on loodud küllalt intrigeeriv situatsioon seiklusrikkaks jätkuks, mida paraku ei järgne. Mingist narratiivist on säilitatud vaid osa, mille ümber saab luua tundeliselamusliku teemaarenduse. Samas pole peategelane tüüp, keda saaks idealiseerida kui kangelast - on ta ju hätta sattunud ennekõike oma edevuse tõttu. Selline ambivalentsus näib olevat iseloomulik tegelastele, kes maskuliinsest eepilisest maailmast on sattunud naistelaulu.

Laulutüübis "Sõahain ja kooluhain" on eespool vaadeldud sündmuskäiku edasi arendatud. Üleloomuliku taime söömisest haigestub vend, kuivõrd õde on tal eelnevalt keelanud taime maitsta. Kuna arstijalt abi ei saada, jookseb õde Jumalde lävele, / Marijide paja ala, kus saab lubaduse, et vend ei sure. Seega toimub siin häda likvideerimine, küll ei too see õele kui kangelasele kaasa jutulikult haaravaid katsumusi ega proovilepanekuid. "Leemelehest" puuduv juurdeliide võib olla ka hilisem. Jumala (Jeesuse) ja Maarja poole pöördumine hädaolukorras tuleb ette ka muudes laulutüüpides, näiteks "Jeesuse surm" või "Ilma parandamine", milles on tegemist mingist maisest miljööst kõrgema korratusega, kus aga sõnaviija osa on taas võrreldamatult väiksem kasvõi muinasjutukangelase omast.

"Uibone näiokene" sisaldab jutuks küllaltki kaasahaaravat ainest: kosjamotiivi, põgenemist, varjupaiga otsimist ja dialooge, püüdmist. Noormehed tahavad raiuda teistest erinevat ounapuud. Neiu puus kuuleb seda ja asub põgenema. Tee viib ta üleloomulikult markeeritud paika (Tooni nurm). Lõpuks põgeneb neiu kalaks järve. Hiljem katsuvad noormehed teda siiski ka välja püüda, mis on mõistetav juba kosimismetafoorina. Osa tegevusest toimub üleloomulikus paigas (Tooni nurme, Manaliste maie pääl), aset leiab transformeerumine (puu neiuks, neiu kalaks) - kõik see, mida kasutab ka müüdist arenenud vanem narratiiv. Samas pole aga sõlmitused nimetatud motiivide vahel eriti ladusad - pole selge, kas on tegemist välise kuju vahetamisega (neiu - õunapuu) või on neiu lihtsalt puu sees. Mis kujul toimub põgenemine, kas inimese või puuna? Miks üldse tahab väiko vello puud hukata - kui ta on lihtsalt jutulik ex machina antagonist, ootaks ka vastuhakku temale. Pole näidatud, kuidas satub uibone näiokene üleloomulikku paika (kaevu hüpates?, linnuga lennates?), mis kujul neiu ikkagi järves eluneb (kalana või veealuse perekonna antropomorfse liikmena?) Sarnased jutustamise seisukohalt "magused kohad" on siin kasutamata jäänud. Kas on võimalik, et narratiivi esitamine protsessina on olulisem narratiivist endast, nagu see regilaulu puhul tundub? Me võime neiut kangelaseks nimetada vaid tingimisi, kuivõrd temaga seonduv on laulus 
kõige kesksem ja kõige sündmusrikkam. Ta ei meenuta kuigivõrd sünkretistlikku kangelast paljude rahvaste vanemas eepikas, nagu seda kirjeldab Eleazar Meletinski (vt 1986: 23 jj). Eepilise kangelasena on ta liiga laialivalguv.

Täieliku narratiivse kao näiteks on "Kosjasõit". Laulutüübid, milles läbiv on kosjamotiiv, võiksid pakkuda arenevat lugu, kuivõrd mingisugune eesmärk kosimise näol püstitatakse juba alguses. "Kosjasõit" pakub variandikirevust, mille ühisosaks ongi ennekõike vaid idee kosjaminekust. Varianditi võidakse keskenduda kas dialoogile neiuga või siis hoopis selle vanematega, mõni lõpeb õnnetu vahejuhtumiga sillal, teised sinnamaale ei jõuagi. Mingisugune (oletatav) ideeskeem või kindlapiirilisem teema - kui poeetiliste üksuste mõtestatud ühendus, mitte aga suvaline valik (Lord 1994: 84) - on siit kaduma läinud ning jäänud kombineerimine üksikmotiividega. Peategelane ei avane dünaamilise isiksusena, tema näol on tegemist otsekui teatrimaskiga, mille tähendus on teadmata. Võib oletada kujutatu kunagist müüdilist tagapõhja, näiteks sõidetakse üle vee - ilmade lahutaja. Teispoolsusse minnakse alati läbi vee ja enamik episoode, mis sisaldavad intriigi, leiavad aset veepiiril (Tarkka 1994: 267). Selles suhtes on kriis sillal otsekui jälg konfliktsusest ktooniliste jõududega, mis iseloomustab vanimat kangelase-kujutelma (vt Meletinski 1986: 73 jj). Võiks oletada, et tegemist on jäänustega mingist müüdist, mille kunagine modaalsus pole leidnud muutuvas inimmõtlemises "väärilist" ümbermõtestamist, mida võis oletada näiteks "Kalmuneiu" puhul.

Vladimir Propi järgi vastanduvad müüt ja sellest lähtunud eepika diametraalselt oma ideelise suunitluse poolest, vaatamata ühisjoontele süzheedes ja kompositsioonis. Eepos ei sünni müüdist mitte vaba arenemise, vaid vastandumise teel (Propp 1955: 33). Jääb kohati mulje, nagu ei alluks regilaululine müüdijätk sellele arenguloogikale, vaid kujutaks endast müüdilise maailmapildi kajastuste rudimenteerumist kuni tundmatuseni vastupidiselt ootuspärasele kangelaseepika tekkimisele.

Vaadeldud laulutüüpides ilmnenud jooned on iseloomulikud kogu setu lüroeepikale laiemalt. Minimaalne keskendatus konfliktile, eriti aga kangelase-kontseptsiooni nõrkus pole loonud pinnast müüdijätkete ümberkujunemisele enam-vähem lineaarse süzheega narratiivi(de)ks. Lüroeepilise regilaulu peategelane ei meenuta eriti sünkretistlikku kangelast paljude rahvaste vanemas eepikas. Mingil põhjusel (tänu naislaulikute domineerimisele, ajaloolisele ja sotsiaalsele eripärale (vt Annist 1969: 41 jj) pole setu ja eesti regilaulus tekkinud kangelasluulet (erinevalt kasvõi karjala eepikast), mistõttu pärandunud aines on kuni uue (ballaadiliku) esteetika ja mõtlemismallide pealetulekuni allunud mingile meile tundmatule printsiibile või printsiibitusele. Vanu müüdikilde ja nende kombinatsioone on kohati nagu püütud "kaasajastada", kuid see pole endaga kaasa toonud uut kvaliteeti.

Valdavates laulutüüpides pole peategelase käitumine ei kangelaslaululikult heroiline ega imemuinasjutulikult nutikas, samas ei saa ta mitte alati ka ballaadiliku "moraalse võitja" kaastundlikku hinnangut. Selline "passiivne kangelane" ongi setu lüroeepiliste regilaulude levinumaid peategelasi, tema äraootavat-kurtvat-needvat-hindavat loomust ei ilmesta kuigi tihti sihikindlad aktsioonid. Tüüpilise kangelase iseloomujooned - lootus iseendale, kalduvus oma jõu ülehindamisele, impulsiivsusele (Meletinski 1986: 76) - ei ilmne setu regilaulu peategelases. Kangelaseepikas ei püüdle kangelane oma isikliku õnne poole (Propp 1955: 44). See pole aga sugugi iseloomulik setu regilaulu passiivsele kangelasele. Kangelase-kontseptsiooni kahjuks räägib ka ta anonüümsus, kui- 
võrd kangelaspoeesias üldiselt on nimeta personaazhid mõeldamatud (Steblin-Kamenski 1979: 174). Eespool vaadeldud nimelised ballaaditegelased (Peeter, Toomas, Maie) on vaid hilisemad erandid.

Seega võime tõdeda, et varemesitatud arenguskeemist (müüt _ kangelaseepika _ ballaad) on setu (ja ka eesti) lüroeepilistel regilauludel haakuvusi ennekõike müüdilise ning ballaadilikuga, mis on ka peamised eepilised kihistused neis. Kangelaseepilise kihistuse puudumine põhjendab ka tõsiasja, miks eesti rahvuseeposes "Kalevipoeg« autentsete regivärsside osakaal äärmiselt väike on: regilauluvaramus lihtsalt puuduvad vähegi sobivad heroilise sisuga arendused ja vastavad tegelased, sest õigupoolest on Kalevipoegki kangelasena vaid Friedrich Reinhold Kreutzwaldi poolt trohheilisse tetrameetrisse imporditud. Sarnane on olukord ka Paulopriit Voolaine etteantud ja Anne Vabarna improviseeritud setu rahvuseeposes "Peko«.

Ootuspäraselt on ka setu regilaulu ideoloogiline ilmapilt peaaegu välja kujunemata - õigupoolest pole selle poole püüeldudki. Kuivõrd kultuurheeros on kollektiivi kui terviku võrdkuju (Meletinski 1960: 87), viitab kangelaseepika puudumine rahvusliku identiteedi küsitavusele või on siis vastavad ideed võõra surve mõjul kaduma läinud. Seega on kangelase ja sündmustiku - kui jutulike dominantide - ebamäärasus ning varieeruvus ühelt poolt regilaulutraditsiooni pikaealisuse tunnuseks, teisalt aga tõestab eepilise pretensiooni hääbumist neis hiljemalt möödunud sajandi lõpuks.

\section{Kirjandus}

Annist, August 1969. "Kalevala" kui kunstiteos. Tallinn.

Annist, August 1985. Tõlkija järelsõna 1959. aasta väljaandele. Kalevala. Tallinn, 479-502.

Hurt, Jakob 1904. Setukeste laulud. Pihkva-Eestlaste vanad rahvalaulud, ühes Räpinä ja

Vastseliina lauludega. Ezimene köide. Helsingi.

Lord, Albert 1994. Skazitel. Moskva.

Lotman, Juri 1991. Kirjandus ja mütoloogia. Kultuurisemiootika. Tallinn, 317-346.

Meletinski, Eleazar 1960. O genezise i putjahh differentsiatsii epitseskihh zhanrov. Russkii Folklor. V. Moskva, Leningrad, 81-101.

Meletinski, Eleazar 1986. Vvedenie v istoritsheskuju poetiku epoza i romana. Moskva.

Merilai, Arne 1991. Eesti ballaad 1900-1940. Tartu.

Pentikäinen, Juha 1986. The Background to the Finnish Creation Myth. Traces of the Central Asian

Culture in the North. Suomalais-Ugrilaisen Seuran Toimituksia 194, 195-211.

Propp, Vladimir 1955. Russkii geroitsheskii epos. Leningrad.

Steblin-Kamenski, Mihhail 1979. Drevneskandinavskaja literatura. Moskva.

Tarkka, Lotte 1994. Other Worlds - Symbolism, Dialogue and Gender in Karelian Oral Poetry.

Studia Fennica. Folkoristica 2 (Songs beyond the Kalevala), 250-298.

Valk, Ülo 1994. Eesti rahvausu kuradi-kujutelm kristliku demonoloogia ja rahvusvahelise folkloori kontekstis: ilmumiskujud. Tartu.

Virtanen, Leea 1974. Tuomaanlaulun maailmankuva. Sampo ei sanoja puutu. Kalevalaseuran Vuosikirja 54. Porvoo, Helsinki, 501-519.

* Esitatud rahvusvahelisel konverentsil Rahvalaul ja -muusika kui identiteedi kandja ja kultuurivahetuse objekt Laulasmaal 20. oktoobril 1996. aastal. 